\title{
LAS RADIOS COMUNITARIAS, OTRA COMUNICACIÓN SOCIALMENTE RENTABLE. EL CASO DE CUATRO EMISORAS DE BOGOTÁ
}

\section{COMMUNITY RADIOS, ANOTHER SOCIALLY PROFITABLE COMMUNICATION. THE CASE OF FOUR BOGOTÁ STATIONS}

\author{
José Ignacio “Iñaki” Chaves-Gil". Corporación Universitaria Minuto de Dios. \\ Colombia. \\ jose.chaves@uniminuto.edu
}

\section{RESUMEN}

El objetivo de este artículo es establecer qué comunicación practican las radios comunitarias de Bogotá a partir de determinar su rentabilidad social aplicando una versión adaptada del Índice de Rentabilidad Social de la Comunicación (Irscom) creado por el grupo de investigación "Laboratorio de Comunicación y Cultura" de la Universidad de Málaga. Estas radios trabajan por una comunicación que permita escuchar a personas y colectivos que, teniendo voz propia, no son tenidos en cuenta. Si hablamos del ejercicio comunicativo de estas radios lo hacemos de una comunicación participativa, dialógica y horizontal; de un espacio de libertad en el que se reconoce el derecho a la comunicación y se democratiza la palabra. La tarea de las radios comunitarias es una labor social que busca la metamorfosis de una realidad las más de las veces ocultada. Su finalidad no es el lucro, sino la escucha y el diálogo abierto a la comunidad para que ésta cuente (narre) y sea tenida en cuenta, que se hagan visibles frente a la sociedad a partir de la comunicación que practican y del papel que juegan en la construcción de tejido social. Se presentan los resultados de la investigación llevada a cabo con cuatro emisoras comunitarias bogotanas estableciendo su rentabilidad con un método que muestra un panorama de sus potencialidades, así como de sus carencias, a la hora de contribuir a la construcción de ciudadanías críticas y participativas desde la comunicación que realizan.

PALABRAS CLAVE: comunicación; radios comunitarias; rentabilidad social; Irscom; metamorfosis; participación.

\section{ABSTRACT}

The objective of this article is to establish what communication the community radio stations of Bogotá practice from determining their social profitability by applying an adapted version of the Social Profitability Index of Communication (Irscom) created by the research group "Communication and Culture Laboratory" from the University of Malaga. These radios work for a communication that allows listening to people and groups that, having their own voice, are not taken into account. If we talk about the communicative exercise of these radios, we do it with a participatory, dialogic and

\footnotetext{
1José Ignacio "Iñaki" Chaves-Gil - Corporación Universitaria Minuto de Dios - UNIMINUTO (Bogotá, Colombia). jose.chaves@uniminuto.edu
} 
horizontal communication; of a space of freedom in which the right to communication is recognized and the word is democratized. The task of community radio is a social work that seeks the metamorphosis of a reality that is often hidden. Its purpose is not profit, but listening and open dialogue to the community so that it counts (narrates) and is taken into account, that they become visible to society from the communication they practice and the role they play in the construction of social fabric. The results of the research carried out with four Bogota community broadcasters are presented, establishing their profitability with a method that shows an overview of their potential, as well as their shortcomings, when contributing to the construction of critical and participatory citizenships from the communication they perform.

KEYWORDS: communication; community radio; social profitability; Irscom; metamorphosis; participation.

\section{Cómo citar el artículo:}

Chaves-Gil, J. I. (2020). Las radios comunitarias, otra comunicación socialmente rentable. El caso de cuatro emisoras de Bogotá. Revista de Ciencias de la Comunicación e Información, 24(2), 57-73

doi: http://doi.org/10.35742/rcci.2019.24(2).57-73

La revolución también se hace con la radio Radio Rebelde

\section{INTRODUCCIÓN}

El objeto de estudio de esta investigación son las radios comunitarias como propuestas comunicativas que trabajan desde la comunidad para hacer oír las voces de aquellas personas y colectivos que no tienen cabida en los llamados medios tradicionales, los medios masivos de difusión de noticias que nos venden como "medios de comunicación".

La labor que desarrollan esas emisoras, desde la comunicación, es una acción que busca la metamorfosis de la realidad social de las poblaciones en las que se enmarcan. Entendiendo que son experiencias de esa "otra" comunicación al margen de la dominante y también de la alternativa (en tanto en cuanto, lo alternativo no significa sin más que sea mejor). Otra comunicación, participativa, dialógica y horizontal, que intenta explicar el mundo de manera distinta, a partir, principalmente, de narrativas propias que promuevan otra manera de entender la realidad para desmontar las distopías del desarrollo existente, que ha sido impuesto, y proponiendo otro rumbo hacia una metamorfosis social que haga que el mundo pueda ser mejor para la mayoría.

La investigación se llevó a cabo con cuatro emisoras comunitarias de Bogotá, midiendo su rentabilidad social con base en el Índice de Rentabilidad Social de la Comunicación (IRSCOM) para poder determinar si su papel como medios comunicativos cercanos a las ciudadanías contribuye a la metamorfosis de una 
sociedad que se transforma a gran velocidad y que, muchas veces, no es consciente de ella.

\section{CONTEXTO}

La radio sigue siendo, a pesar de las nuevas tecnologías, uno de los medios más utilizados y escuchados en el mundo. Continúa siendo un medio accesible, económico y con una gran capacidad de difusión y por lo tanto de penetración (según datos de la Unesco, en los países en desarrollo, al menos el $75 \%$ de los hogares tienen acceso a la radio, en el mundo existen cerca de 44.000 emisoras de radio y suponen una de las tecnologías más accesibles ya que cubren más del $70 \%$ de la población mundial).

Es eficiente y eficaz, siendo, por lo general, la comunicación que practica activa y participativa. Por eso se le puede considerar como un medio ciudadano para la transformación social.

Lleva muchos años amenazada de desaparecer, pese a que mantiene su identidad y sigue consolidada como un valor seguro en la comunicación. Guilhon la define como "un medio invisible, en una era de predominio de la imagen. Es un medio oral, en una época en que lo que tiene valor es lo escrito. Es un medio fugaz, en una civilización vuelta hacia la posteridad. Es un medio descentralizado, en un sistema concentrador" (2009: 139).

La radio es el medio de la oralidad, algo que en América Latina, territorio de identidades orales ancestrales, sirve para mostrar las realidades sociales y políticas de los países del continente. Aicardi afirmaba que

"Su actividad más importante es la transmisión de programas deportivos, radionovelas y la selección de los últimos éxitos musicales grabados; calla cuando se lo ordenan las autoridades, pero ha sido capaz de ser artífice indirecto en la creación de dictaduras y movimientos revolucionarios y, con la misma facilidad, ha contribuido a derrotarlos. (...) es indiscutiblemente el medio de información masiva y comunicación social de mayor importancia y más poderoso de América Latina" (1981: 151).

\subsection{Comunicación y radio en Colombia}

En Colombia, la Radiodifusora Nacional, identificada como HJN, fue, en 1929, pionera en el medio radiofónico, situando al país como uno de los cuatro de América Latina (junto a El Salvador, Paraguay y Venezuela) en los que la primera iniciativa para transmitir a través de las ondas partió desde la esfera pública.

La Resolución 415 de abril 13 de 2010, del Ministerio de las TIC "Por la cual se expide el Reglamento de Radiodifusión Sonora y se dictan otras disposiciones", establece que las emisoras de radio se clasifican en cuatro grupos según: la gestión de su servicio, la orientación de su programación, la tecnología para transmitir y el cubrimiento territorial del servicio que prestan. La Ley 1341, de las TIC, define los principios y conceptos sobre la sociedad de la información y la organización de las 
tecnologías de la información y las comunicaciones, estableciendo que los servicios de radiodifusión sonora (art. 56) según su denominación legal, deben contribuir a difundir la cultura, afirmar los valores esenciales de la nacionalidad colombiana y a fortalecer la democracia. En los programas radiales deberá hacerse buen uso del idioma castellano. Por los servicios de radiodifusión sonora no podrán hacerse transmisiones que atenten contra la Constitución y las Leyes de la República o la vida, honra y bienes de los ciudadanos (2009: 25).

Si nos atenemos a la orientación de la programación, las estaciones radiodifusoras se dividen, según el artículo 18 (MinTIC, 2010: 6) de la resolución citada, en tres categorías que son:

- comerciales: con ánimo de lucro aunque haya finalidades educativas, culturales, informativas, científicas o de entretenimiento, a través de una programación que intenta satisfacer a la audiencia.

- interés público: de titularidad estatal, está dirigida a cubrir necesidades comunicacionales del Estado y la ciudadanía, buscando lograr el bienestar general y mejorar la calidad de vida de la población. No hay ánimo de lucro.

- comunitarias: está orientada a abrir espacios de debate y expresión que permitan el encuentro de las distintas identidades culturales del país. Han de promover la democracia y la participación para lograr una convivencia pacífica.

Según datos del Ministerio de Tecnologías de la Información y las Comunicaciones (MinTIC), a noviembre de 2018 existían en Colombia mil quinientas setenta y ocho emisoras radiofónicas, de las cuales seiscientas sesenta y siete eran comerciales, seiscientas veintiséis comunitarias y doscientas ochenta y cinco de interés público.

\subsection{La comunicación y las radios comunitarias}

La comunicación de las radios comunitarias es participativa, abierta a la gente, y alterativa, porque busca un cambio en positivo para la mayoría de la población al facilitar el acceso para que se dé el diálogo. Su manera de entender lo comunicacional nace de las propuestas epistemológicas de la teoría crítica de la comunicación latinoamericana (Beltrán, 1981; Díaz Bordenave, 2011; Pasquali, 2007, y otros), a partir del modelo de comunicación que surge del cuestionamiento de las teorías difusionistas y modernizadoras y que plantea "otra" comunicación, cuestionadora de los medios, de la información y del poder que los maneja.

En el ámbito latinoamericano, las redes de comunicación elaboraron un documento sobre la comunicación para la inclusión y el bien común, que se recoge en el texto del Foro Social de las Américas ${ }^{2}$, celebrado en Quito (Ecuador) en julio de 2004, en el que plantearon:

\footnotetext{
${ }^{2}$ Otra comunicación es posible. Carta pública de las redes latinoamericanas de comunicación en apoyo a CRIS. Consultada el 23 de septiembre de 2010. Disponible en http://www.alainet.org/es/active/6588
} 
Entendemos a la comunicación como un derecho humano fundamental que nos asiste desde que nacemos y que todas y todos debemos ejercerlo a lo largo de la vida con igualdad de oportunidades. Por esa naturaleza, la comunicación debe servir para la inclusión social, para que a través de ella se expresen los conflictos y diferencias en diálogo con todos los pareceres, en la búsqueda del bien común.

Esa inclusión y ese bien común es una labor que deben llevar a cabo las emisoras comunitarias para buscar evitar que el panorama radial en América Latina se convierta en un espacio en el que "la gran mayoría de las estaciones radiofónicas son vehículos en pequeña escala para cuñas comerciales, canciones populares, noticias y promoción publicitaria sobre un modelo norteamericano". (Hale, 1979: 130).

Merayo engloba las radios comunitarias dentro de la categoría de radios públicas, ya que considera que la radio pública se tiene que entender

atendiendo no tanto a la titularidad jurídica como a la función social que cada emisora desempeña realmente. Es decir, lo que a mi juicio convierte de verdad en pública una emisora no es tanto el régimen de propiedad como sus contenidos cuando éstos se orientan verdaderamente a la construcción de ciudadanías. (2007: 16).

Sus prácticas comunicativas son muy distintas a las dominantes, no tienen relación con el desarrollo occidental ni con un cambio social sin rumbo; sino que se enmarcan en esa "otra" comunicación que es participativa, que se constituye desde el diálogo y el compromiso con el reconocimiento de las diferencias, reconociendo al otro para que forme parte del proceso comunicativo y que éste le haga ser protagonista de su realidad social. Una comunicación que, pese a no estar asumida totalmente por las instituciones educativas, va adquiriendo entidad con las iniciativas habidas en otras latitudes (Barranquero y Sáez, 2010).

Planteamos el concepto de radio comunitaria desde tres características que deben ser intrínsecas a su actividad: que no haya ánimo de lucro en su labor, que la comunidad en la que se desempeña tenga el control sobre emisora y que la propia comunidad participe activamente en el desarrollo y actividad.

La comunicación practicada por las emisoras comunitarias es una comunicación horizontal, participativa, dialógica. Una comunicación que se podría calificar como "desde abajo", en el sentido dado por Isabel Rauber, historiadora y científica social cubano-argentina, al expresar que las revoluciones sociales desde abajo son:

procesos integrales permanentes de transformaciones en lo social, político, cultural, económico, ideológico y ético, procesos raizalmente articulados a los de construcción de nuevas relaciones de poder, a la gestación y el desarrollo de un nuevo tipo de poder, propio del nuevo tipo de sociedad superadora del capitalismo (y la hegemonía del capital) que se busca y se va construyendo: la sociedad horizontal (2011: 85).

Para López Vigil las radios comunitarias son aquellas que están al servicio de la ciudadanía para combatir los poderes económico, político, religioso y mediático: 
han sido y seguirán siendo de oposición a cualquier sistema que ponga los haberes sobre los seres, que discrimine a las personas por miopías de raza, sexo o credos, que permita que a unos pocos les sobre lo que a tantos les falta. Aunque parezca obsoleto en tiempos postmodernos, queremos seguir sintiendo nuestra - como decía bíblicamente el Che-cualquier injusticia que se cometa contra cualquier ser humano en cualquier parte del mundo (2000: 332).

Se establece que en las radios comunitarias, la sociedad civil se planta ante la exclusión comunicativa que sufre y se plantea hacer "otra" comunicación. Las radios comunitarias son una de las maneras de situar a la gente, desde la comunicación, al frente del control de lo informativo-comunicacional para establecer su propia programación. Son instrumentos para la comunicación personal (comunicar-se) y para la comunicación social (comunicar-nos).

\section{OBJETIVO DE LA INVESTIGACIÓN}

La finalidad de la presente investigación ha sido llevar a cabo la aplicación del Índice de Rentabilidad Social de la Comunicación (Irscom adaptado) a las cuatro emisoras comunitarias de Bogotá y su zona de influencia para medir su rentabilidad social, evaluando si con ello contribuyen de alguna manera a la metamorfosis de las realidades sociales de sus entornos.

Tabla 1. Listado de las radios comunitarias de Bogotá por orden alfabético.

\begin{tabular}{|l|l|l|}
\hline Emisora & Dirección & Población \\
\hline La Norte & Carrera 8 No.162-26 & Bogotá \\
\hline Luna estéreo & Calle 17 no. $9-11$ & Chía \\
\hline Suba al aire & Carrera 90 No. 147-44 & Bogotá \\
\hline Vientos Stéreo & Carrera 6 Este No. 29-59 Sur & Bogotá \\
\hline
\end{tabular}

Fuente: Elaboración propia a partir de los datos facilitados por Grupo Comunicarte y actualizados tras contactar o visitar las propias emisoras.

Para la investigación de las radios comunitarias de Bogotá se han introducido pequeñas modificaciones en aras de, según nuestro criterio, procurar que las variables se ajusten con mayor fidelidad a la realidad social y comunicativa del país. Además de las seis categorías establecidas por COMandalucía en la ficha y, en nuestro caso, sus cuarenta y tres variables, hemos añadido, sin puntuación que compute para la calificación global de su rentabilidad, una categoría que hemos denominado "in-dependencia" para determinar si la emisora tiene relación directa con algún tipo de organización política, sindical, social o religiosa y, en caso de que exista, si interviene en la elaboración de la programación. Esto también se ha establecido así dada la casuística observada de que gran parte de las emisoras hacen proselitismo de tipo confesional con alguna religión o culto religioso. 
El índice Irscom pretende ser útil para mejorar la calidad, desde un punto de vista de rentabilidad social, de las radios comunitarias al indicar cuestiones que contribuyan a que, desde la construcción colectiva, se mejoren sus dinámicas comunicativas. No es una herramienta para evaluar y luego sancionar en función de los resultados, sino que pretende "ser un estímulo para la mejora del trabajo en las emisoras y su incidencia ciudadana".

Creemos que las radios comunitarias son una apuesta por "otra" comunicación con la que la ciudadanía quiere paliar la habitual exclusión sufrida por parte de los medios masivos tradicionales.

Entendemos que los medios comunitarios hacen parte, en línea con lo que planteara Enzensberger, de aquel grupo que usa los medios de un modo emancipador permitiendo que la sociedad esté presente en todo el proceso comunicativo, reconociendo su identidad y su papel. Pudiendo ejercer una acción comunicativa que contribuya a las transformaciones sociales. Estos medios no están bajo un control político centralizado y todas las personas, delante o detrás de los micrófonos, se convierten en transmisores y receptores de un proceso colectivo de comunicación.

Tabla 2. Enzensberger: Elementos para una teoría de los medios de comunicación.

\begin{tabular}{|l|l|}
\hline Uso represivo de los medios & Uso emancipador de los medios \\
\hline Programa de control central & Programas descentralizados \\
\hline Un transmisor, muchos receptores & Cada receptor, un transmisor en potencia \\
\hline Inmovilización de individuos aislados & Movilización de las masas \\
\hline $\begin{array}{l}\text { Conducta de abstención pasiva respecto al } \\
\text { consumo }\end{array}$ & Interacción de los participantes, feedback \\
\hline Proceso de despolitización & Proceso de aprendizaje político \\
\hline Producción por especialistas & Producción colectiva \\
\hline Control por propietarios o burócratas & $\begin{array}{l}\text { Control socializado por organizaciones } \\
\text { autogestoras }\end{array}$ \\
\hline
\end{tabular}

Fuente: H.M. Enzensberger (1974: 43)

\section{METODOLOGÍA: LA COMUNICACIÓN Y LA RENTABILIDAD SOCIAL DE LAS RADIOS COMUNITARIAS}

Las radios comunitarias, como actores sociales con responsabilidad por la comunicación que practican, que no buscan los beneficios económicos sino la promoción de la participación de la población en el proceso comunicativo, es oportuno evaluar su rentabilidad social:

es un medio que se define mejor por su función que por sus aspectos técnicos (...) es una herramienta de comunicación para ayudar a construir el futuro de 
las gentes que son su razón de ser y su misma alma. Sus rendimientos son sociales (...). (M. Beltrán, 1996: 6).

La comunicación entendida como "la relación comunitaria humana consistente en la emisión-recepción de mensajes entre interlocutores en estado de total reciprocidad, siendo por ello un factor esencial de convivencia y un elemento determinante de las formas que asume la sociabilidad del hombre" (Pasquali, 2007: 101).

O cómo "el proceso de interacción social democrática que se basa sobre el intercambio de símbolos por los cuales los seres humanos comparten voluntariamente sus experiencias bajo condiciones de acceso libre e igualitario, diálogo y participación" (Beltrán, 2014: 293).

Para determinar esa rentabilidad social de las radios comunitarias se aplicó el Índice de Rentabilidad Social de la Comunicación (IRSCOM) elaborado por el grupo de investigación Laboratorio de Comunicación y Cultura - COMandalucía de la Universidad de Málaga. El Irscom es una herramienta que busca establecer el nivel de rentabilidad social de los medios desde una aproximación cualitativa-cuantitativa, asignando valores numéricos a las variables que conforman las diferentes categorías del índice.

Con el índice se evalúa la rentabilidad "en un momento en el que, desde el ámbito académico, convivían propuestas de investigación de interés en la comunicación pública y en establecer parámetros que contribuyan a construir ciudadanía desde unos medios más plurales y democráticos" (Olmedo, 2014: 375).

Las categorías que contiene este instrumento son seis: la gestión, el capital social, la articulación territorial, la programación, la presencia en internet y la infraestructura. A partir del resultado se busca deducir el "valor comunitario" de las radios y de sus prácticas comunicativas.

El índice se aplicó a las cuatro emisoras recogidas en la tabla 1. La valoración se propone desde el lugar de las propias emisoras y sus comunidades de potenciales oyentes, puesto que son sus respuestas las que determinan si son socialmente rentables.

Para COMandalucía, el concepto "rentabilidad social" se entiende como el valor de la prestación de un servicio de interés público que promueve, esencialmente, la libertad de expresión y el derecho a la comunicación. Ponderamos la pertinencia de su aplicación para medir las radios comunitarias al ser éstas parte del tercer sector de la comunicación que sirve a la ciudadanía. Ello porque la intención del Irscom es "poner en valor la función social, articuladora y dinamizadora de los medios audiovisuales" (Olmedo, 2015: 378).

Las seis categorías mencionadas están determinadas por un total de 43 variables cuya sumatoria ofrece un rango de puntuación de entre 74 y 120 puntos.

Tabla 3. Puntuaciones mínima y máxima por categorías. 
LAS RADIOS COMUNITARIAS, OTRA COMUNICACIÓN SOCIALMENTE RENTABLE. EL CASO DE CUATRO EMISORAS DE BOGOTÁ

\begin{tabular}{|l|r|r|}
\hline Categoría & Puntuación mínima & Puntuación máxima \\
\hline Gestión & 15 & 25 \\
\hline Capital social & 16 & 26 \\
\hline Articulación territorial & 10 & 15 \\
\hline Programación & 22 & 36 \\
\hline Presencia en internet & 6 & 10 \\
\hline Infraestructuras & 5 & 8 \\
\hline Puntuación total & $\mathbf{7 4}$ & $\mathbf{1 2 0}$ \\
\hline
\end{tabular}

Fuente: elaboración propia a partir del IRSCOM adaptado.

Cada categoría se explica de la siguiente manera:

- La categoría "gestión" facilita información sobre el funcionamiento interno de la emisora. Considerando que las condiciones en Colombia son algo más complejas y, tal vez, precarias, las variables preguntadas fueron: el tipo de entidad; existencia de estatutos (en lugar de si se cumplen o no), y si tienen "misión" y "visión" de su organización que, por normativa legal, han de constar en el manual de estilo con el que deben contar y tener a disposición del público. Añadiendo si se realizan reuniones, de qué tipo y con qué frecuencia y si son presenciales.

- Conocer el número de personas que trabajan en la radio, si hay mujeres, afrodescendientes, indígenas, LGBTI o discapacitadas, nos da el "capital social”, para evaluar cómo construyen ciudadanía a partir de la gente con la que cuentan. También las personas voluntarias y los grupos o colectivos con los que interactúan.

- La participación en redes o colectivos sociales y si practican otras actividades ajenas a las puramente radiofónicas (culturales, deportivas,...) nos dan la "articulación territorial". Se ha añadido si están participadas (ya que algunas emisoras comunitarias en Colombia se vinculan con ciertos grupos religiosos) y por ¿cuáles? grupos, en caso de que la respuesta fuera afirmativa.

- Para la categoría "programación" se tienen en cuenta aspectos como la producción de informativos locales propios; los temas, y la variedad de estos, de su parrilla; la participación de colaboradores, socios o voluntarios en esa programación; el intercambio de programas con otras radios o redes de ellas; la música; lo compartido en red; los programas en la calle y una pregunta nueva sobre cómo es la realización de los programas emitidos (propia, externa o enlatada) y cuáles de ellos son llevados a cabo por la comunidad (en las tipos de programas se ha incluido la variable "interculturalidad").

- La "presencia en internet" de la emisora se basa en si cuenta con página web, sobre su mantenimiento y su actualización. Además, se ha incluido si utilizan blogs $u$ otras herramientas digitales; cuál es la participación activa en redes y otros recursos multimedia; si hacen emisión on line, y si usan podcasts.

- Y por último, la "infraestructura" significa dejar constancia de cómo son los espacios en los que realizan sus actividades radiales: medios físicos y 
técnicos, estudios, salas de redacción, aulas y una pregunta sobre si cuentan con videoteca, fonoteca o biblioteca, aspecto relevante ya que detrás de las emisoras suele haber entidades culturales, populares o religiosas).

Mauricio Beltrán plantea que bajo el paraguas de radios comunitarias se pueden englobar cuatro tipos de emisoras: por megafonía, por grupos de producción (arrendando materiales y espacios), a través de los casetes foro (programas pregrabados para ser escuchados y debatidos en público) y por estaciones de radio (tradicional uso del espacio radioeléctrico) (M. Beltrán, 1996)

La radio será comunitaria si sale desde abajo, nace de la comunidad, con ella, por y para ella. Sin más pretensiones que disponer del micrófono para que todas las voces que lo deseen puedan decir y puedan ser escuchadas. Eso permite a la gente ser reconocida, poder narrar sus historias, reclamar sus derechos, denunciar si llega el caso. Pero siempre desde su oralidad, porque las personas, la ciudadanía, sobre todo en América Latina, tierra de oralidades y sentidos, siempre ha tenido voz, aunque no se les haya escuchado.

Las gentes de las emisoras comunitarias no pretenden persuadir, no quieren ocupar el primer lugar del ranking por audiencia o por volumen de publicidad. Tampoco quieren, aunque tal vez deberían, tumbar el gobierno de turno, desarmar una alcaldía o un partido político, o quitarle oyentes o anuncios a las radios comerciales que les aburren con su música, con sus anuncios, sus jingles y sus programas ajenos y alejados de las realidades sociales de la mayoría de las comunidades de un país.

Su definición debería darse desde su papel en la comunicación y no como herramienta de la misma. Es su identidad la que la define, no su infraestructura o su tecnología "La radio comunitaria (...) está hecha por y para una población determinada. Sus rendimientos son sociales más que económicos (...)" (M. Beltrán, 1996: 6)

En esa línea, la idea que soporta el Irscom es poder "identificar y poner en valor aquellas experiencias comunicacionales que están apostando por una comunicación local de calidad y un servicio público por y para la ciudadanía", tal se recoge en la página web del grupo de investigación. Ya que, para COM-andalucía, las emisoras vertebran el tejido social y esta cualidad está determinada por la capacidad para movilizar y hacer participar.

El Irscom es una manera de estudiar la rentabilidad social de los medios de manera distinta a lo que habitualmente se hace: medir las audiencias, el consumo de medios o los beneficios que producen "existe en el campo de la comunicación una carencia de herramientas orientadas a una evaluación que aborde plenamente la rentabilidad de los medios desligada del impacto en la audiencia traducido en el exclusivo rendimiento comercial." (Olmedo, 2014: 373). O en los últimos años, la tan nombrada y sobrevalorada responsabilidad social corporativa o empresarial.

\section{RESULTADOS}


Presentamos los datos evaluados a partir de la aplicación de la ficha Irscom y las cifras obtenidas en las distintas variables que conforman las seis categorías del índice. Con esos resultados se puede establecer una clasificación en función de la puntuación global final obtenida por las emisoras.

Presentamos una tabla con las puntuaciones por categorías y la puntuación final obtenida por cada emisora. Esto solamente con una intención didáctica que nos sirva para tener un panorama de la rentabilidad social de las radios comunitarias de Bogotá.

Para COM-andalucía se ponderan los resultados estableciendo unos rangos de clasificación general: si la puntuación resultante de la ficha se situaba entre 0 y 59 puntos era de rentabilidad muy baja; entre 60 y 73, de rentabilidad baja; entre 74 y 89, media; entre 90 y 99 serían óptimas y más de 100 las situaría en rentabilidad máxima.

Aplicando esa graduación a las cuatro emisoras de nuestro estudio podemos observar que tanto La Norte como Luna Estéreo serían de rentabilidad media; que Vientos Estéreo tendría una rentabilidad óptima, y que Suba al Aire alcanzaría el rango de rentabilidad máxima, con un margen de mejora de otros dieciséis puntos.

Tabla 4. Rentabilidad social de las emisoras comunitarias.

\begin{tabular}{|l|l|r|l|r|r|}
\hline & Puntuación por categoría & La Norte & $\begin{array}{l}\text { Luna } \\
\text { Estéreo }\end{array}$ & $\begin{array}{l}\text { Suba al } \\
\text { Aire }\end{array}$ & $\begin{array}{l}\text { Vientos } \\
\text { Estéreo }\end{array}$ \\
\hline \multirow{4}{*}{$\begin{array}{c}\text { Rentabilidad } \\
\text { social }\end{array}$} & Capital social & 20 & 16 & 24 & 16 \\
\cline { 2 - 7 } & Gestión & 16 & 16 & 18 & 16 \\
\cline { 2 - 7 } & Articulación en el territorio & 9 & 4 & 14 & 15 \\
\cline { 2 - 7 } & Programación & 31 & 28 & 35 & 34 \\
\cline { 2 - 7 } & Internet & 6 & 6 & 8 & 5 \\
\cline { 2 - 7 } & Infraestructura & 6 & 6 & 5 & 5 \\
\hline \multirow{2}{*}{ Total } & & $\mathbf{8 8}$ & $\mathbf{7 6}$ & $\mathbf{1 0 4}$ & $\mathbf{9 1}$ \\
\hline
\end{tabular}

Fuente: elaboración propia a partir de las fichas cumplimentadas por las emisoras.

Estas puntuaciones solamente muestran la realidad de las emisoras desde el punto de vista establecido por el índice Irscom. Es decir, que estas radios comunitarias pueden tener otras fortalezas $u$ otras debilidades que no salen a la luz con esta ficha porque no se contemplan entre sus categorías o variables.

La intención de este estudio es mostrar, nunca demostrar, la rentabilidad social de las radios comunitarias investigadas a partir de unas categorías y unas variables ya determinadas con anterioridad y aplicadas a estas estaciones radiofónicas como prueba piloto que nos permita definir si es pertinente y coherente. Serán las propias 
emisoras las que evalúen si el estudio refleja aspectos que pueden ser tenidos en cuenta por las personas responsables de las mismas para que puedan considerarlos $\mathrm{y}$, de parecerles oportuno, realizar las modificaciones necesarias tendentes a mejorar esa calificación.

La discriminación de las respuestas dadas por las personas responsables de las emisoras nos da un panorama general de las radios en función de las seis categorías y los ítems que las componen.

Por categorías, en capital social las cuatro emisoras alcanzan la nota mínima, dieciséis (16) puntos; siendo Suba al Aire la que, con veinticuatro (24) puntos, más se acerca a la puntuación máxima que situamos en veintiséis.

En gestión, todas están un poco por encima del puntaje mínimo establecido en quince (15). Puede que no sea el punto fuerte de las emisoras comunitarias estudiadas, pero procuran llevar la estación cumpliendo las obligaciones mínimas.

En articulación con el territorio, tanto La Norte, con nueve (9) puntos, como, sobre todo, Luna Estéreo, con apenas cuatro (4), están por debajo del mínimo situado en diez (10). Eso denota que hay que trabajar más la presencia y las relaciones con otras emisoras y colectivos.

En la categoría programación es donde radica la mayor fortaleza de las cuatro emisoras estudiadas; estando todas ellas por encima de la mitad del rango mínimomáximo (22-36). Eso es un dato muy relevante porque nos dice que su parrilla está cercana a la realidad de su comunidad y abierta a la participación de la misma.

En presencia en internet, Vientos Estéreo no alcanza el mínimo de seis (6) puntos quedándose a la puerta con cinco (5). En su descarga habría que señalar que, en mayor o menor medida, todas las emisoras están trabajando en la renovación y mejora de su presencia en la web y de las tecnologías que eso conlleva.

En cuanto a la categoría de infraestructuras, las cuatro aprueban por los pelos. Suba al Aire y Vientos Estéreo alcanzan la mínima de cinco (5) puntos, mientras que La Norte y Luna Estéreo superan por un punto, obteniendo seis (6), la puntuación más baja.

Una valoración general de los resultados nos permite deducir que la labor de las radios comunitarias de Bogotá es ardua y que la pasión y las ganas por hacer radio son las que les permiten superar las muchas dificultades con las que se enfrentan a diario. No sólo las condiciones técnicas sino también las humanas, sociales o económicas.

Aun así, la evaluación global del índice de rentabilidad social de la comunicación, Irscom, nos permite aventurar que su labor como emisoras comunitarias y su acción comunicativa las sitúa como entidades socialmente rentables. Superan con buena nota las calificaciones determinadas en la ficha, y aunque tienen falencias en algunos aspectos, la nota global final es satisfactoria. 
La suma total de las puntuaciones de las seis categorías evaluadas sitúa a Suba al Aire con ciento cuatro (104) puntos, treinta más que la puntuación mínima y solamente seis por debajo de la máxima. Eso la hace aparecer como una radio comunitaria de rentabilidad máxima. En segundo lugar, Vientos Estéreo obtiene noventa y un puntos (91) lo que la coloca como de rentabilidad óptima; y La Norte, con ocho y ocho puntos (88), y Luna Estéreo, con setenta y seis (76), las hace aparecer como medios comunitarios de rentabilidad media.

Por lo que podemos concluir que las cuatro emisoras comunitarias son socialmente rentables, cumplen con creces con su labor como medios sociales de proximidad insertos en sus comunidades y que están abiertos a la participación de la ciudadanía. Su labor es fundamental y necesaria para esa "otra" comunicación de la que venimos hablando: accesible, dialógica y participativa. Son medios que comunican, que sirven para la relación de la población, para que ésta sienta que forma parte de su propia realidad y que tiene qué decir y a través de donde hacerlo.

Son radios comunitarias que son sentidas como ciudadanas porque cuentan con la ciudadanía y hacen a ésta serlo. Al abrir sus micrófonos a que la gente narre según sus estéticas y sus éticas, forman parte de esa "resistencia creativa" de la que habla Omar Rincón y que hace que se constituyan como medios representativos de la oralidad regional, porque "nos juntan como latinoamericanos", porque nos permite "imaginarnos como narradores sociales" y porque su existencia "nos da derecho a la palabra." (Rincón, 2007).

Del Irscom, podemos afirmar que es un instrumento válido para hacer una medición distinta y cualificada de la parte social de los medios comunitarios. Que es la más importante de los mismos, ya que su valor no está ni en la cantidad de publicidad que pautan ni en el lugar que ocupan en los índices de audiencia. Su logro es estar cerca de la ciudadanía y servir de punto de partida y de llegada, en un viaje de ida y vuelta, de la comunicación. Porque su papel está en comunicar, en que las gentes narren y escuchen, sean escuchadas y tenidas en cuenta.

En la investigación hemos presentado el índice Irscom y mostrado su composición y aplicación en los medios comunitarios para, a través del mismo, determinar la rentabilidad social de las emisoras comunitarias que han formado parte de este trabajo.

El instrumento está conformado por seis categorías, junto a sus correspondientes variables, que nos permite tener una valoración general de las radios comunitarias, identificando sus potencialidades y sus falencias con la única finalidad de determinar su rentabilidad para informarlas y que sepan cuáles han sido los resultados. Sin que eso suponga, por supuesto ninguna sanción, ni siquiera un llamado de atención. Solamente una constatación de unos datos y de lo que ellos suponen. A partir de ahí, son los propios medios los que tendrán que evaluar su sentido y tomar, si así lo deciden, las medidas que consideren oportunas para alcanzar una mayor puntuación en el resultado global de la ficha, actuando sobre aquellos aspectos en los que su evaluación haya sido menos satisfactoria. 
Como parte destacada del tejido social, las radios comunitarias pueden contar con este instrumento para tener un mayor conocimiento de sus características en cada una de las categorías: capital social, es decir la participación de personas y colectivos en su funcionamiento; gestión de la emisora, en cuanto a la documentación que muestre su actividad, su compromiso y sus convenios con otras radios o instituciones, así como los mecanismos de participación ciudadana; la articulación con el territorio, a partir de sus vínculos con emisoras, organizaciones e instituciones y en redes; la programación que elaboran y emiten, cómo y quién la produce; la presencia en internet, página web y otros recursos tecnológicos digitales, y la infraestructura, sus recursos físicos y técnicos para el desarrollo de su labor.

Con las respuestas a las variables que se incluyen en cada categoría y su evaluación posterior, podemos concluir que el índice Irscom es una herramienta apropiada, pertinente y útil para medir los aspectos sociales de las emisoras.

Tras su aplicación, hemos hecho una evaluación de sus resultados por categorías, elaborando un cuadro por cada una de ellas en los que aparecen las diferentes puntuaciones obtenidas por cada variable informada.

Los puntajes obtenidos han sido contabilizados y analizados para determinar qué lugar ocupan en el accionar particular de cada emisora comunitaria. Aunque solemos medir comparando, en este caso esa comparación no supone decir que una emisora sea mejor o peor que otra. Solamente arrojan datos que nos dan una perspectiva general de las capacidades de las radios en las distintas áreas medidas. Esos valores son una fotografía de lo que cada emisora hace o tiene en las distintas categorías para que ellas mismas sepan dónde están y si les interesa intervenir para modificar esos resultados de cara al futuro.

Cierto que hemos elaborado también un cuadro final con las puntuaciones globales por categoría que nos da un resultado último, lo que nos permite decir cuán rentables socialmente son cada una de las emisoras en las que se ha aplicado la ficha. Eso con la única intención de ver totalizadas sus capacidades y situar una nota con la que terminar este cuarto objetivo de nuestra investigación y poder elaborar una evaluación de cierre.

Las emisoras comunitarias estudiadas cumplen con buena nota la labor social que mide el índice de rentabilidad social de la comunicación. Las cuatro nos ofrecen una muy buena labor en esos ámbitos de todas ellas. Eso nos muestra que la evaluación es oportuna y que los resultados son coherentes con lo que se les supone a unos medios que son ciudadanos, cercanos a la comunidad y cuyo papel es trabajar por la transformación social a partir de la comunicación que practican.

Su punto fuerte es la programación, categoría en la que se puede observar cómo es la participación de la comunidad. Siendo la participación, como hemos planteado a lo largo de este trabajo, un aspecto fundamental de esa "otra" comunicación a la que queremos propender, que se dé la misma es una buena muestra de que hay diálogo y que se facilita el acceso a estos medios comunitarios.

\section{CONCLUSIONES}


Podemos concluir que las emisoras comunitarias que forman parte de esta investigación son socialmente rentables, incluso con una puntuación media alta.

Y podemos entender que esa rentabilidad es una manera de contribuir a la metamorfosis de unas realidades la mayor parte de las veces ignoradas. Le aportan a la transformación social en sus comunidades, puesto que los aspectos valorados con las categorías y variables de la ficha IRSCOM evalúan facetas de las radios que tienen que ver con su integración en la comunidad en la que se asientan, con la participación de ésta en su funcionamiento y desarrollo y con el capital social que atesora al hacer partícipes a personas y colectivos de su entorno.

Pese al poco respaldo institucional, a la falta de recursos y a las dificultades técnicas, la rentabilidad social de las cuatro emisoras comunitarias es buena. Tanto su acción social como su labor comunicativa las presenta como socialmente provechosas, válidas para sus comunidades.

La rentabilidad social mide precisamente lo que tienen de social las emisoras de las localidades, sin tener en cuenta los aspectos puramente económicos y mercantilistas que son los que importan a las radios comerciales. Son sociales, son cercanas, son abiertas a la participación y al diálogo. Escuchan con otros oídos y narran con otras voces. Rentan socialmente, por lo que promueven el cambio.

Forman parte de la comunidad, son representativas de la misma, que a su vez participa de ellas. Comunican y contribuyen a la cultura oral local, abriendo sus ondas a las narraciones de la gente, lo que hace que se sientan parte, que sean reconocidas, que construyan ciudadanía y que promuevan metamorfosis sociales.

En las emisoras comunitarias se intenta trabajar al servicio de la comunidad, de la comunicación entre sus miembros, lo que contrarresta, en la medida de sus posibilidades, la labor de los sistemas mundiales de difusión de noticias para las masas que muchas veces le apuestan más al silencio que a la información (Kapuscinski, 2009). Las radios comunitarias dicen más que callan.

Si a eso le sumamos esa otra manera de comunicar y de hacer radio podremos concluir que las emisoras comunitarias tienen un destacado papel en la metamorfosis social de sus comunidades y en la transformación de sus realidades.

\section{REFERENCIAS BIBLIOGRÁFICAS}

Aicardi, R. (1981). "Notas sobre la historia de la radiodifusión en Latinoamérica". En Bassets, LI. De las ondas rojas a las radios libres. Barcelona, Gustavo Gili.

Atton, C. (2002). Alternative media. Londres, Sage.

Barranquero, A. y Sáez, Ch. (2010). "Comunicación alternativa y comunicación para el cambio social democrático: sujetos y objetos invisibles en la enseñanza de las teorías de la comunicación”. Ponencia II Congreso Internacional AE-IC, Málaga. 
Beltrán, L. R. (1981). “Un adiós a Aristóteles: la comunicación horizontal”. En Communicaçao y Sociedade, año III, no 6, septiembre, pp. 5-35. Traducido para la U. Católica Boliviana de La Paz por J.L. Aguirre.

Beltrán, M. (1996). Los caminos de la radio comunitaria. Bogotá, Ministerio de Comunicaciones.

Chaparro, M. (ed.) (1997). Radiotelevisión pública local y alternativa. Perspectivas. Jerez de la Frontera, EMA-RTV y Ayuntamiento de Jerez de la Frontera.

Díaz Bordenave, J. (2011). Aportes a la comunicación para el desarrollo. Asunción, Arandura editorial. Disponible en http://www.portalguarani.com/3029 juan diaz bordenave/22205 aportes a la co municacion para el desarrollo 2011 por juan diaz bordenave.html

Downing, J. et al. (2001). Radical Media: Rebellious Communication and Social Movements. London: Sage.

Enzensberger, H.M. (1974). Elementos para una teoría de los medios de comunicación. Barcelona, Anagrama.

Girard, B. (2002). Radio Apasionados: Experiencias de radio comunitaria en el mundo. Quito, CIESPAL.

Guilhon, O. (2009). "La radio y el derecho a la comunicación”. En Zepeda, J. y Fdez. Bogado, B. (comp.) La radio: entre la comunicación y el poder. Holanda, RNW.

Gumucio, A. (2001). Haciendo olas. Historias de comunicación participativa para el cambio social. La Paz, Plural.

Hale, J. (1979). La radio como arma política. Barcelona, Gustavo Gili.

Kapuscinski, R. (2009). Cristo con un fusil al hombro. Barcelona, Anagrama.

López Vigil, J.I. (2000). Manual urgente para radialistas apasionados y apasionadas. Quito, Radialistas.net. En copyleft.

Merayo, A. (2007). La radio en Iberoamérica. Evolución, diagnóstico prospectiva. Sevilla, Comunicación Social.

MinTIC (2010). "Reglamento del Servicio de Radiodifusión Sonora". Disponible en: https://mintic.gov.co/portal/604/articles-3797 documento.pdf

MinTIC (2009): "Ley 1341 de las Tecnologías de Información y las Comunicaciones". Disponible en: https://mintic.gov.co/portal/604/articles-8580 PDF Ley 1341.pdf

Olmedo, S. (2014). "Irscom: la responsabilidad social de los medios y la construcción de indicadores democráticos". En Chaparro, M. Medios de proximidad: 
participación social y políticas públicas. Sevilla, iMEDEA / Luces de Gálibo.

Pasquali, A. (2007). Comprender la comunicación. Barcelona, Gedisa.

Rauber, I. (2011). Dos pasos adelante, uno atrás. Lógicas de superación de la civilización regida por el capital. Bogotá, desde abajo.

Rincón, O. (2007). Ya no es posible el silencio. Textos, experiencias y procesos de comunicación ciudadana. Bogotá, C3FES.

Rodríguez, C. (2013). "Comunicación ciudadana en Montes de María, Colombia". Revista Luciérnaga. Politécnico Colombiano Jaime Isaza Cadavid. Año 5, Edición 9. Medellín, Colombia. ISSN 2027 - 1557. Disponible en: file:///Users/j.ignaciochavesg./Downloads/DialnetComunicacionCiudadanaEnMontesDeMariaColombia-5529526\%20(2).pdf

Sharpe, J. (1996). "Historia desde abajo". En Burke, P. (ed.): Formas de hacer historia. Madrid, Alianza.

Marí, V. (2007). "El enfoque de la comunicación participativa para el desarrollo y su puesta en práctica en los medios comunitarios". En Razón y Palabra, № 71, febrero abril 2010. Disponible en: http://www.razonypalabra.org.mx/N/N71/index.html 